\title{
Cecal Leiomyoma: Can We Attempt Endoscopic Resection?
}

\author{
Kanthi Rekha Badipatla ${ }^{\mathrm{a}, \mathrm{b}, \mathrm{d}}$, Chandana Kamireddy ${ }^{\mathrm{b}}$, Masooma Niazic ${ }^{\mathrm{c}}$, \\ Suresh Kumar Nayudu, ${ }^{\mathrm{a}, \mathrm{b}}$
}

\begin{abstract}
Gastrointestinal leiomyomas are smooth muscle tumors arising from the muscularis mucosae, muscularis propriae and possibly from smooth muscle of the vessel wall. Management depends on the size, location and the clinical scenario. Endoscopic snare cauterization with or without saline lift has been described in literature for tumors involving the left colon. To the best of our knowledge, endoscopic resection of right colon leiomyoma was never attempted in the past. We present a case of cecal leiomyoma which was resected endoscopically.
\end{abstract}

Keywords: Gastrointestinal leiomyoma; Endoscopic mucosal resection

\section{Introduction}

Gastrointestinal leiomyomas are rare benign tumors incidentally detected during endoscopy in asymptomatic population. Clinical presentation may vary from non-specific abdominal pain to life-threatening complications like massive bleeding and perforation requiring emergent surgical interventions. Our case is first of its kind in cecum which is managed by endoscopic mucosal resection resulting in complete excision and resolution of symptoms.

\section{Case Report}

A 51-year-old woman was referred to gastroenterology clinic for screening colonoscopy. At the initial visit, the patient reported intermittent episodes of rectal bleeding for the last few

\footnotetext{
Manuscript accepted for publication November 23, 2016

${ }^{a}$ Division of Gastroenterology, Bronx Lebanon Hospital Center, 1650 Grand Concourse, Bronx, NY 10457, USA

bepartment of Medicine, Bronx Lebanon Hospital Center, 1650 Grand Concourse, Bronx, NY 10457, USA

${ }^{\mathrm{c}}$ Department of Pathology, Bronx Lebanon Hospital Center, 1650 Grand Concourse, Bronx, NY 10457, USA

${ }^{\mathrm{d} C}$ Corresponding Author: Kanthi Rekha Badipatla, 1770 Grand Concourse Apt 6B, Bronx, NY 10457, USA. Email: kanthirb@gmail.com
}

doi: https://doi.org/10.14740/gr736e months prior to the visit. She noted bleeding was painless and admixed with stools. She denied any prior abdominal pain, nausea, vomiting or altered bowel habit. She did not report any changes in appetite or weight.

Her past medical history was significant for hypertension, diabetes mellitus, dyslipidemia and vitamin D deficiency. She did not undergo any surgical procedures in the past. There were no gastrointestinal malignancies diagnosed in her immediate or distant family members. She never used tobacco products, alcohol or recreational drugs. She was not allergic to any medications.

On initial evaluation, she was afebrile with heart rate of 86 beats per minute and blood pressure of $160 / 100 \mathrm{~mm} \mathrm{Hg}$. Abdomen was non-distended, soft and non-tender to palpation. On auscultation, bowel sounds were noted to be normoactive. Cardiorespiratory and neurological examination was within normal limits.

Laboratory workup revealed a normal hemoglobin of 14.7 $\mathrm{g} / \mathrm{dL}$, hematocrit $44 \%$, white cell count of $12.6 \times 10^{3} / \mu \mathrm{L}$ and platelets of $255 \times 10^{3} / \mu \mathrm{L}$. Her electrolytes, renal and liver function tests were within normal limits.

She underwent flexible colonoscopy under monitored anesthesia care. On colonoscopy, she was noted to have two sessile, smooth polypoid lesions measuring $20 \mathrm{~mm}$ (Fig. 1) and 6

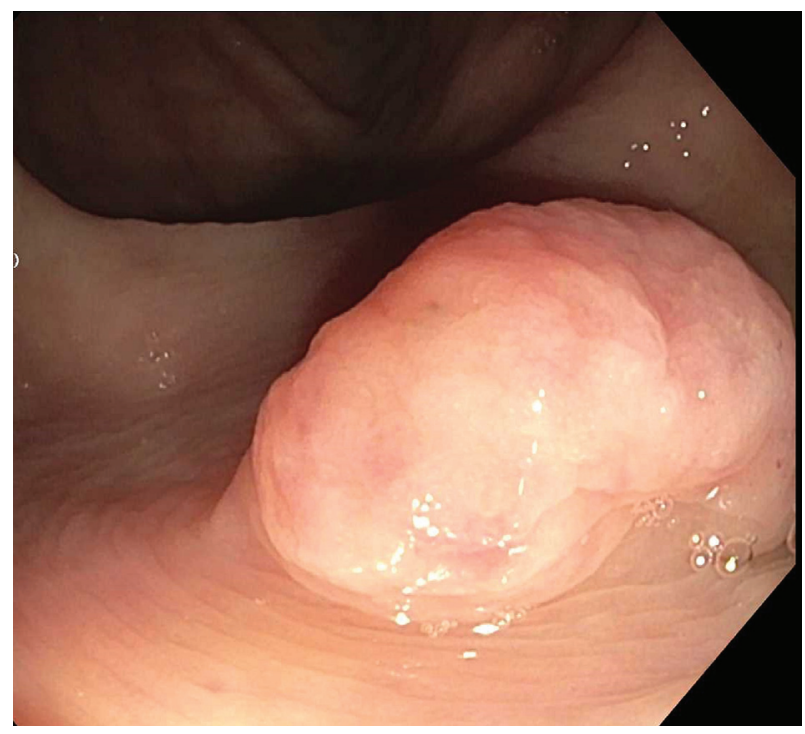

Figure 1. Endoscopic view of one $20 \mathrm{~mm}$ smooth sessile polypoid lesion in the cecum. 


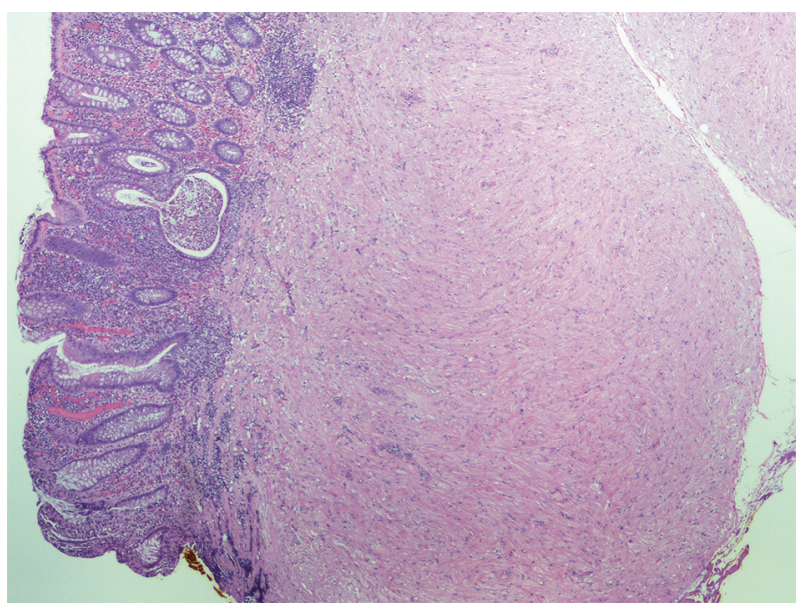

Figure 2. Section of leiomyoma of cecum showing a downward proliferation of muscularis mucosae which elevated the mucosa.

$\mathrm{mm}$ in the cecum. Small external hemorrhoids were also noted during retro-flexion. The polyps were injected with saline and resection was accomplished using a hot snare. Retrieval of the $20 \mathrm{~mm}$ polyp was done using a Roth net. There was no bleeding noted during or after resection.

Histopathological examination of the lesions was consistent with leiomyoma (Fig. 2) with interlacing fascicles of spindle shaped cells and cigar shaped nuclei (Fig. 3). Immunohistochemical staining was positive for smooth muscle actin (Fig. 4).

\section{Discussion}

Gastrointestinal leiomyomas are smooth muscle tumors arising from the muscularis mucosae, muscularis propriae and possibly from smooth muscle of the vessel wall in the bowel [1]. They are also known to be slow growing tumors predominantly seen in men [1] and mean age of detection is 62 years [2]. Though they are known to occur in the entire gastrointestinal tract, esophagus is reported as the most common site [3].

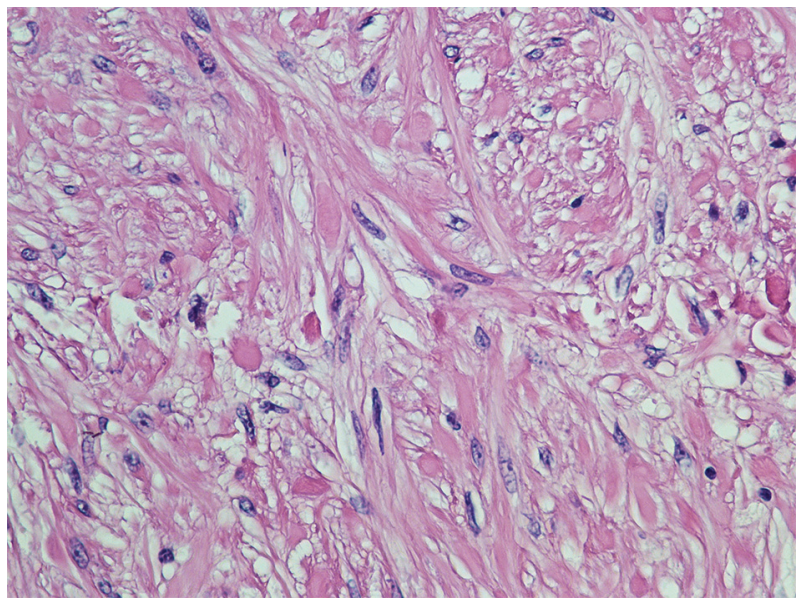

Figure 3. Cecal leiomyoma on high magnification showing interlacing fascicles of spindle shaped cells with cigar shaped nuclei.

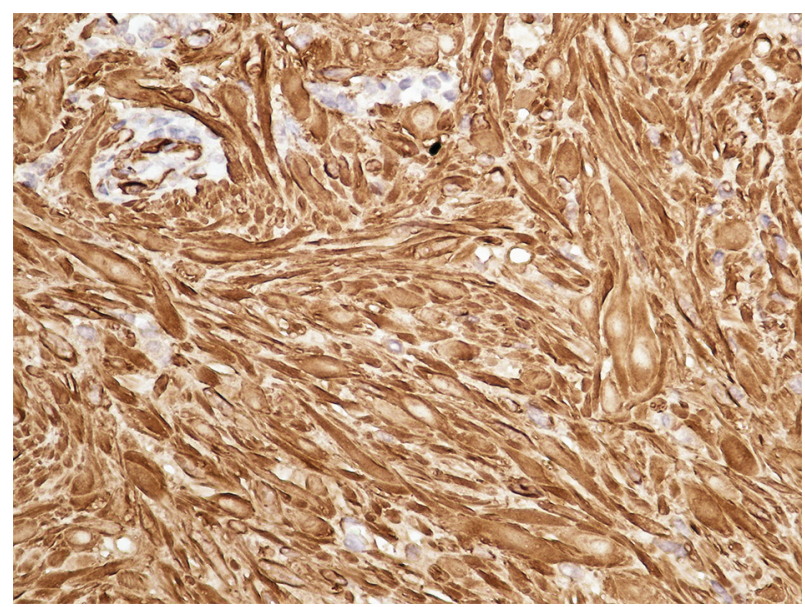

Figure 4. Immunostaining strongly positive for smooth muscle actin.

Colonic leiomyomas are uncommon with a reported incidence of $3 \%$ of all the gastrointestinal leiomyomas. In the large intestine, recto-sigmoid and descending colon are the most common sites of origin [4]. To the best of our knowledge, right colon involvement occurs less commonly than the left.

Hatch et al reviewed the literature on colonic leiomyomas reported between 1875 and 1996. There were a total of 16 cases of leiomyoma in the cecum and ascending colon out of the total 87 cases in the whole colon, making this tumor in the right colon a very rare one [5].

Tumors involving the cecum can be benign or malignant. Malignant tumors in turn are primary and metastatic. Benign tumors involving the cecum may be hyperplastic polyps, adenomatous polyps and lipomas.

Leiomyomas are usually solitary tumors and rarely multiple lesions can present as leiomyomatosis syndrome [6]. Location of the lesion may be intraluminal, intramural, or extra-luminal. Leiomyomas can be asymptomatic and can be detected during routine colonoscopy. When symptomatic, the symptoms range from abdominal pain, altered bowel habit and bleeding [7]. Large leiomyomas are also known to cause compressive and obstructive symptoms based on location. Bleeding from leiomyoma can vary from being detected on occult blood testing $[8,9]$ to more overt bleeding. Massive blood loss needing transfusion, perforation, obstruction, intussusception [10] and hemoperitoneum [11] are among the few complications described which generally require surgical intervention.

On endoscopy, they appear as tumors with smooth surface mimicking routinely encountered polyps. Other endoscopic appearances have also been described including the vascular ectasia and ulceration [7].

Management depends on the size, location and the clinical scenario. Endoscopic snare cauterization with or without saline lift has been described in literature especially for tumors involving the left colon $[9,12]$. This partly could parallel the higher incidence of these tumors in left colon. Endoscopic submucosal dissection has also been done for leiomyomas of the esophagus and stomach [13]. However, to the best of our knowledge, there have not been reports of such therapy being attempted in the right colon with none reported so far in the 
cecum. Our case proves that such treatment in cecum can be safely attempted with proper technique and expertise.

Alternatively, the use of endoscopic ultrasound to assess precisely the location and origin of tumor for feasibility of endoscopic resection has also been suggested in literature [14]. However, it should be borne in mind the fact that most of these tumors mimic epithelial polyps in their gross appearance during colonoscopy. This may end up in interventionists attempting resection without prior ultrasound evaluation.

Cases are also managed by laparoscopic resection [15]. Massive bleeding and giant tumors causing compression are some of the clinical scenarios necessitating bowel resection which were also described in literature $[7,16,17]$.

There is minimal chance of recurrence after resection of such tumors. We are not aware of any specific recommendations for follow-up after resection, although this is probably based on the clinical scenario and type of treatment and completeness of resection.

\section{References}

1. Agaimy A, Wunsch PH. True smooth muscle neoplasms of the gastrointestinal tract: morphological spectrum and classification in a series of 85 cases from a single institute. Langenbecks Arch Surg. 2007;392(1):75-81.

2. Miettinen M, Sarlomo-Rikala M, Sobin LH. Mesenchymal tumors of muscularis mucosae of colon and rectum are benign leiomyomas that should be separated from gastrointestinal stromal tumors - a clinicopathologic and immunohistochemical study of eighty-eight cases. Mod Pathol. 2001;14(10):950-956.

3. Wang ZQ, Wang S, Ye YJ, Kang YL, Sun KK, Zheng HF. [Gastrointestinal mesenchymal tumors: a clinical pathologic and immunohistochemical study of 210 cases]. Zhonghua Wei Chang Wai Ke Za Zhi. 2007;10(1):11-16.

4. Kemp CD, Arnold CA, Torbenson MS, Stein EM. An unusual polyp: a pedunculated leiomyoma of the sigmoid colon. Endoscopy. 2011;43(Suppl 2 UCTN):E306-307.

5. Hatch KF, Blanchard DK, Hatch GF, 3rd, WertheimerHatch L, Davis GB, Foster RS, Jr., Skandalakis JE. Tumors of the appendix and colon. World J Surg. 2000;24(4):430436.
6. Padberg BC, Emmermann A, Zornig C, Germer M, Schroder S. [Leiomyomatosis of the colon: case report and literature review]. Pathologe. 2007;28(2):161-165.

7. Chen CW, Jao SW, Wu CC, Ou JJ, Hsiao CW, Chao PC. Massive lower gastrointestinal hemorrhage caused by a large extraluminal leiomyoma of the colon: report of a case. Dis Colon Rectum. 2008;51(6):975-978.

8. Costantini R, De Nicola P, Bianco F, Cotroneo AR, Iezzi R, Di Bartolomeo N, Innocenti P. Tumor vs non-tumor origin of occult and obscure gastrointestinal bleeding requiring hospitalization. Tumori. 2007;93(5):461-466.

9. Urgesi R, Pastorelli A, Zampaletta C, Masini A, Pelecca G, Faggiani R, Anti M. Obscure-occult bleeding: resolution of unexplained chronic sideropenic anaemia by colonoscopic removal of a colonic leiomyoma. BMJ Case Rep. 2011;2011.

10. Sayer RA, Amundsen CL. Giant pelvic retroperitoneal leiomyoma arising from the rectal wall. Obstet Gynecol. 2003;101(5 Pt 2):1132-1134.

11. Di Roma A, Cafferati M, Ghersi T, Roberti L, Do D. [Hemoperitoneum caused by leiomyoma of the colon]. Minerva Chir. 1996;51(9):725-727.

12. Jovanovic I, Cvejic T, Popovic D, Micev M. Endoscopic removal of pedunculated leiomyoma of the sigmoid colon (case report and literature review of dignostic and treatment options). Acta Chir Iugosl. 2006;53(1):87-89.

13. Hulagu S, Senturk O, Aygun C, Kocaman O, Celebi A, Konduk T, Koc D, et al. Endoscopic submucosal dissection for premalignant lesions and noninvasive early gastrointestinal cancers. World J Gastroenterol. 2011;17(13):1701-1709.

14. Naem M, Stanich PP, El-Dika S. Incidental subepithelial sigmoid colon lesion. Clin Gastroenterol Hepatol. 2015;13(1):A32.

15. Hawa N, Robinson J, Obias V. Cystically degenerated leiomyoma of the rectosigmoid managed laparoscopically at 13 weeks of gestation. J Minim Invasive Gynecol. 2012;19(3):383-385.

16. Sagnotta A, Sparagna A, Uccini S, Mercantini P. Giant extraluminal leiomyoma of the colon: rare cause of symptomatic pelvic mass. Int Surg. 2015;100(5):805-808.

17. Moussi A, Nouira R, Bourguiba B, Daldoul S, Zaouche A. A rare cause of lower gastrointestinal bleeding. Tunis Med. 2010;88(12):961-963. 